\title{
Multimedia Information Management System for College Physical Education Course
}

\author{
Fei Zhang ${ }^{1, \text { a }}$ \\ ${ }^{1}$ Yangzhou polytechnic Institute, physical education Department, Yangzhou225000,jiangsu \\ a email
}

Keywords: Sports, multimedia network teaching platform design, education sports network

\begin{abstract}
As the development of computer technology, the field of multimedia technology, communications technology and education are developed. There has been to explore the educational technology as representative of new educational model, wherein the multimedia network teaching is quite prominent. In order to present the mature campus network-based, Internet-based technology, computer technology, multimedia technology, modern communications technology were designed. The development of a sports-oriented multimedia network teaching platform is very necessary. This paper introduces the basic theory and the development of multimedia network teaching background, analyzes the multimedia network teaching platform in higher education in the promotion requirements. The application of relevant technology did the analysis and use of application modules planning which were more relevant presentation. In the standard multimedia network teaching platform design criteria, we discusses the design guidelines for sports discipline multimedia network education platform, then put forward the overall structure and function model.
\end{abstract}

\section{Introduction}

With the rapid development of economic globalization, advancement of science and technology, the development of information technology, communication technology, network technology and multimedia visualization techniques can be described with each passing day. These modern techniques have been deeply integrated into people's daily lives $[1,2]$. The emergence and development of new science and technology in bringing convenience to people but also gradually influence and change people's traditional way of life. With the computer information technology, the development of multimedia network technology, so humanity has entered a new era of knowledge and networks [3]. Reform and development of education, the level of scientific and technological knowledge innovation determines a country's comprehensive national strength and its ability to compete in the entire world [4].

Research and problem-solving of this paper is that demonstrating the advantages of multimedia network teaching platform in the sports teaching process [5]. Summarize and analyze multimedia network teaching platform break the limitations of traditional college physical education and promote the multimedia network teaching platform. Universities physical education took full advantage of the internet resource sharing. Multimedia network teaching platform was for colleges and universities. Various sports information resource site for effective and reasonable integration subsequently of complement each other's purpose. To break the traditional sports teaching space and time limits for some reason, it failed to establish a platform of multimedia network teaching students. The general sports enthusiasts can be anywhere in sports multimedia network teaching platform to learn, to achieve the best teaching resources optimization [6-8].

Computer network timeliness and interactivity can be revelatory, as more college students and non-sports enthusiasts in school online learning guidance. The PE teaching is a bilateral activities practical and highly participatory. The current resources on the network is small relative to other disciplines, the lack of systematic and integrity. For sports teaching, the operation of an exemplary and ideal for use imitative form of multimedia presentation of content. 


\section{The overall design of system framework}

2.1 The basic structure and working principle platform

Multimedia network teaching platform used the latest B/S (browser / server) structure, the structure was shown in Fig. 1. Features of the structure are as follows: the client application environment for the standardization of a common Web browser, all applications are stored on a Web server. Direct download easier to manage and maintain, because the client does not need special software, when upgrading network application, simply can be updated the server software. This structure has good scalability, B/S structure using standard TCP/IP communication protocol, schools may need at any time according to their development expansion of the system.

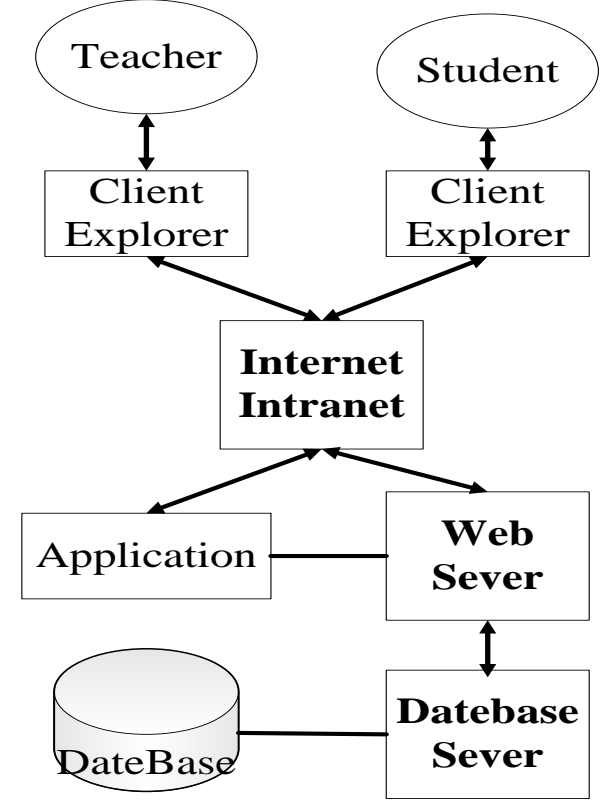

Figure 1. Multimedia network teaching platform chart

The working principle of the system: timely access to teachers and students through the browser multimedia network teaching platform. Students using a personal computer connected to the device through the browser and the server side. The sports teaching content related learning, sports query resource information between teachers and students communication, personal data upload and other operations. Managers and PE teachers college multimedia network teaching platform can be stored in the browser content server to update and maintain. The latest sports teaching resource information to the server, while the students for online, students make sports guidance. After the Web server storage system, the various application modules completed the customer's applications. It receives client user requests and converted to a database which request to interact with the database server. The interaction results in the way Web pages which can request to observe the results. The database server and storage system was for the database management software. Database operates according to the Web server sends a request, the results transmitted to the Web server.

\subsection{System framework}

University sports curriculum multimedia management system is mainly a multimedia file browsing, retrieving multimedia files, statistics, multimedia files, upload multimedia files, user registration, data management and systems management. How to achieve good online multimedia file compression was decompression of multimedia files. Fig. 2 is a diagram of the overall framework of system. 


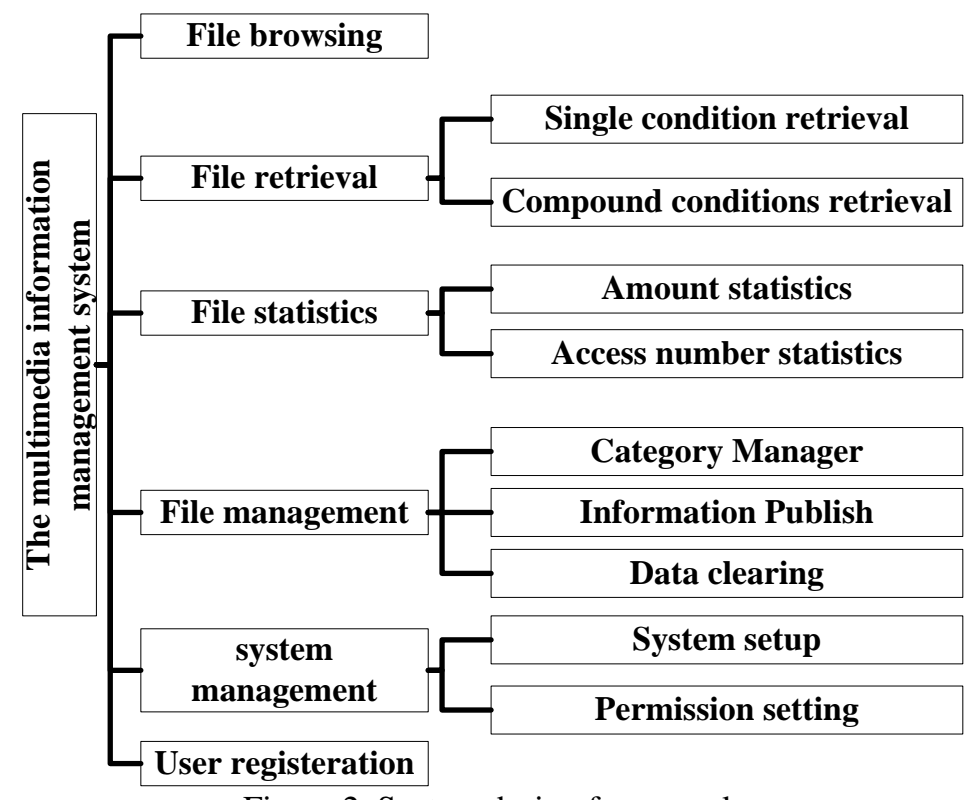

Figure 2. System design framework

In framework of the overall design of system, it mainly planning figure the relationship between the function of the simple system and the whole system.

\section{Results and discussion}

In the traditional process of college physical education, physical education teacher teach technical action mainly through action analysis to explain and demonstrate in person to complete. But in the process, many technical difficulties are the movement, which has done in an instant teachers teaching in this area. It will be restricted traditional teach method, students are unable to comprehend the essentials of the image of the sport and the technical movements. The multimedia network technology in teaching physical education will be a good solution to this problem. Through multimedia technology for image freeze and slow-release technology, the application of FLASH technology can be a good show to be described. Live sub-module logical structure of teaching physical education under module and implementation was shown in Fig. 3. Some teaching physical education video was shown in Fig. 4.

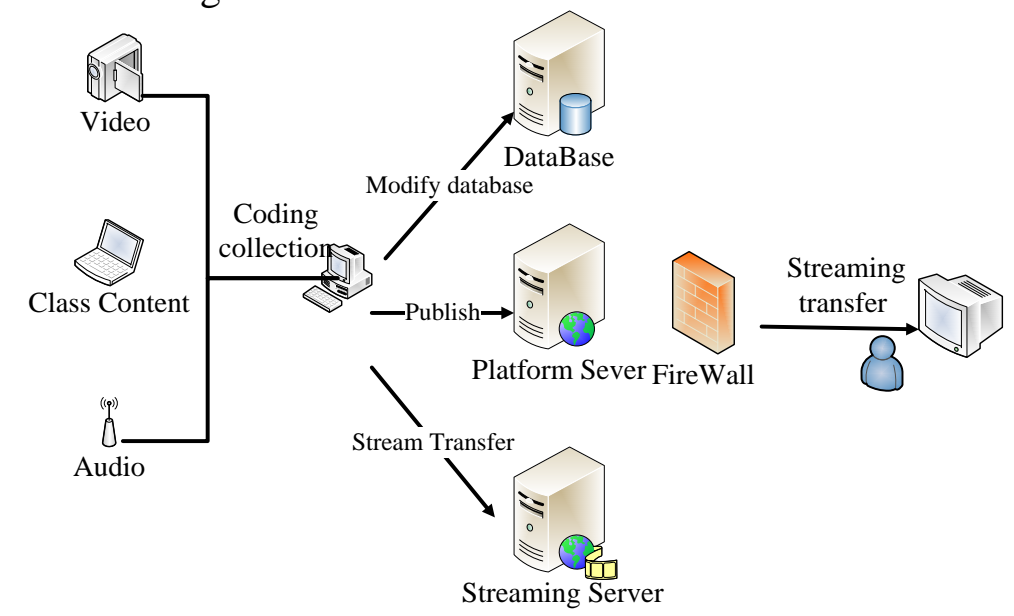

Figure 3. Live sub-module logical structure of teaching physical education 

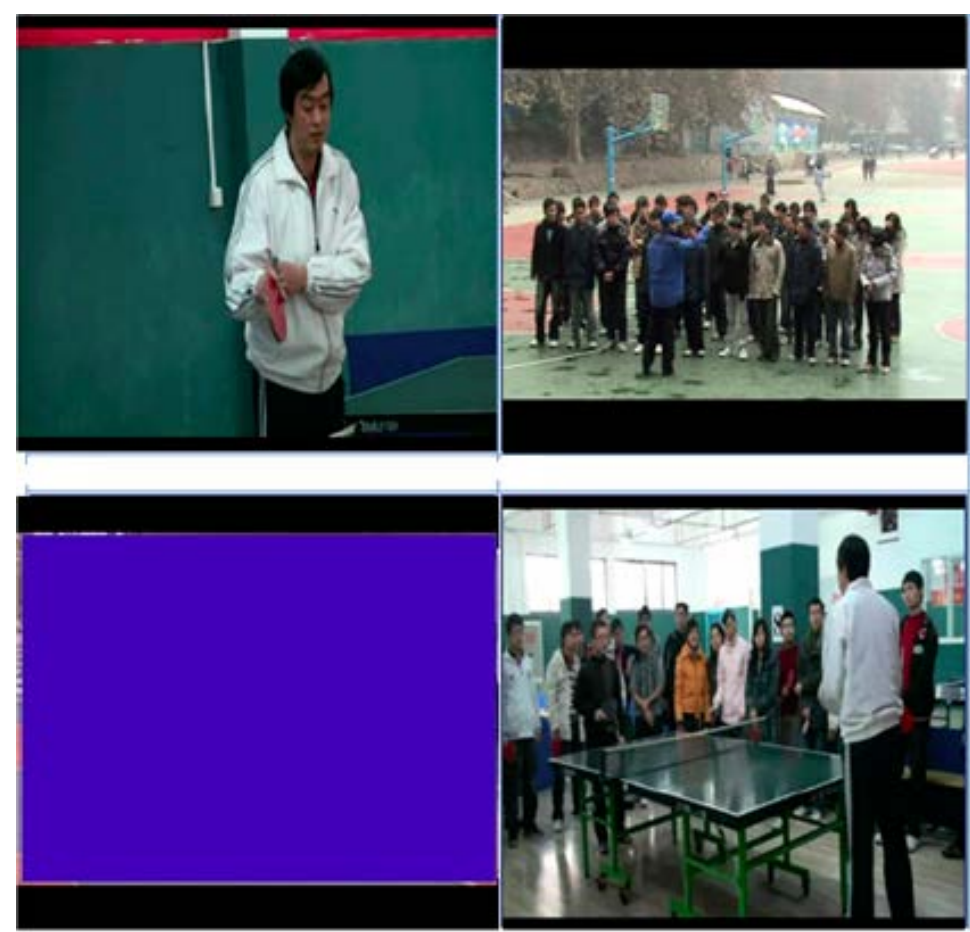

Figure 4. Teaching physical education video

\section{Summary}

In theory teaching, we can use some multimedia network teaching techniques of the original text on display through multimedia content. So it not only rich empty words teaching but also improve students' interest in learning. Multimedia network teaching also can be a good use of micro-teaching, so that teaching with good guidance. Teachers through photographic camera equipment to the student class technical operation aspects. As video recording, and then uploaded to the computer equipment, the use of multimedia technology produce decomposed with slow motion video playback in the student learning process. Results showed that student self-evaluation and collective evaluation play good teaching feedback effects.

\section{References}

[1] Gao Decheng and Wang Jianguo, "Texture Classification Based on Nonsubsampled Directional Filter Banks and Support Vector Machines,” 2010 Second Asia-Pacific Conference on Information Processing (APCIP 2010),2010.

[2] Davies R S, Dean D L, Ball N. Flipping the classroom and instructional technology integration in a college-level information systems spreadsheet course[J]. Educational Technology Research and Development, 2013, 61(4): 563-580.

[3] Y.Yang and L.K.yang, "Neural Network Based on GA-BP Algorithm and its application in the Protein Secondary Structure Prediction, ” Chinese . of Biomedical Engineering (English Edition), vol.15,pp.1-9,2006.

[4] T.Ji and H.Shi, "Soft Sensor Modeling for Temperature Measurement of Texaco Gasifier Based on an Improved RBF Neural Network, " IEEE international Conference on Information Acquisition,pp.1147-1151,2006.

[5] T.Song, M.Jamshidi, R.R.Lee,et al., “A Novel Weighted Probabilistic Neural Network for MR Image Segmentation," IEEE International Conference on System,Man and Cybernetics, pp.2501-1506,2005.

[6] Multimedia information retrieval and management: Technological fundamentals and applications[M]. Springer Science \& Business Media, 2013. 
[7] Y.L.Gao and Z.Z.Zhang, "Modulation Recognition Based on Combined Feature Parameter and Modified Probabilistic Neural Network," 6th World Congress on Intelligent Control and Automation, pp.2954-2958,2006.

[8] Chung C H, Pasquini L A, Koh C E. Web-based learning management system considerations for higher education[J]. Learning and Performance Quarterly, 2013, 1(4): 24-37. 